\title{
Immunogenic properties of renal cell carcinoma and the pathogenesis of osteolytic bone metastases
}

\author{
FRANCESCA PERUT ${ }^{1}$, ELISABETTA CENNI ${ }^{1}$, RONALD E. UNGER ${ }^{3}$, \\ C. JAMES KIRKPATRICK ${ }^{3}$, ARMANDO GIUNTI ${ }^{1,2}$ and NICOLA BALDINI ${ }^{1,2}$ \\ ${ }^{1}$ Laboratory for Pathophysiology of Orthopaedic Implants, Istituti Ortopedici Rizzoli, Via di Barbiano 1/10; \\ ${ }^{2}$ Department of Orthopedic Surgery, University of Bologna, Istituti Ortopedici Rizzoli, \\ Via Pupilli 1, 40136 Bologna, Italy; ${ }^{3}$ Institute of Pathology, Johannes Gutenberg \\ University, REPAIR Lab Langenbeckstrasse 1, 55101 Mainz, Germany
}

Received July 21, 2008; Accepted October 1, 2008

DOI: 10.3892/ijo_00000266

\begin{abstract}
The immunogenic properties of renal cell carcinoma (RCC) on bone osteolysis were investigated. mRNA expression of three proinflammatory cytokines, monocyte chemotactic protein-1 (MCP-1), interleukin-6 (IL-6) and interleukin-8 (IL-8), were determined in a panel of RCC lines (CRBM 1990, ACHN and Caki-1). Moreover proinflammatory cytokine mRNA expression and protein levels of adhesion molecules, intercellular adhesion molecule-1 (ICAM-1) and E-selectin, on human umbilical vein endothelial cells (HUVEC) incubated with the conditioned media from RCC lines were evaluated. RCC express mRNA of MCP-1, IL- 6 and IL- 8 that may induce a proinflammatory phenotype in endothelial cells. mRNA expression of IL-6, and IL-8 was induced on HUVEC treated with the conditioned media from RCC lines and mRNA and protein levels of ICAM-1 and E-selectin were also increased. This study demonstrates the immunogenic properties of renal cell carcinoma, such as pro-inflammatory cytokine secretion and the induction of adhesion molecules (ICAM-1 and E-Sel) by endothelial cells. ICAM-1 binds lymphocyte function-associated antigen-1 (LFA-1), which is expressed by pre-osteoclasts, so that, the observed proinflammatory phenotype in HUVEC may also favour osteoclast recruitment in bone metastases microenvironment. Osteolysis in bone metastases, mediated by this pathway, may be further potentiated by the pro-angiogenic properties of RCC.
\end{abstract}

Correspondence to: Dr Francesca Perut, Laboratory for Pathophysiology of Orthopaedic Implants, Istituti Ortopedici Rizzoli, Via di Barbiano 1/10, 40136 Bologna, Italy

E-mail: francesca.perut@ior.it

Key words: renal carcinoma, endothelial cells, adhesion molecules, osteoclast, inflammation

\section{Introduction}

Renal cell carcinoma (RCC) is an immunogenic neoplasm, as shown by the presence of frequent infiltration of tumor tissue with cells of the immune system (1) and a rare spontaneous regression and clinical responses to immunotherapies (2). Angiogenesis has a relevant role in the progression of the metastatic process of RCC. RCC is characterized by rich neovascularization and expression of angiogenesis-related factors, such as fibroblast growth factor-2 (FGF-2), vascular endothelial growth factor (VEGF) and matrix metalloproteinase types 2 and 9 (3). Bone metastases from RCC are highly vascularized and predominantly osteolytic. Histological analysis has demonstrated a significant presence and activation of osteoclasts in these lesions (4). Little is known about the relationship between the inflammation process and bone resorption in this neoplasm.

Adhesion molecules for leukocytes (CAMs) are usually expressed by endothelial cells activated by inflammatory stimuli such as interleukin-1, endotoxin and tumor necrosis factor- $\alpha(\mathrm{TNF}-\alpha)(5)$. CAMs may have a role in metastases formation (6). E-selectin, involved in the adhesion of neutrophils, monocytes, and CD4+ 'memory' $\mathrm{T}$ lymphocytes to the target tissue endothelium, has also been demonstrated to mediate the rolling of prostate tumor cells to the bone marrow endothelium (7). CAMs have a role in the metastatic dissemination of renal carcinoma (6) and promote neoangiogenesis, favouring the persistence of the neoplasm $(8,9)$. Endothelial CAM expression could favour both the adhesion of neoplastic cells and the recruitment of circulating osteoclast precursors, contributing to the pathogenesis of osteolytic metastases. CAM expression promotes osteoclast precursor recruitment to the sites of bone resorption $(10,11)$ and in bone metabolism (12). Pre-osteoclasts, derived from haemopoietic precursors of the bone marrow and of the peripheral blood (13), express lymphocyte functionassociated antigen-1 (LFA-1) $(12,14)$, that binds ICAM-1 expressed by inflammed endothelium. The binding of vascular cell adhesion molecule-1 (VCAM-1) and $\alpha 4 \beta 1$-integrin is involved in the interaction between stromal cells and osteoclast precursors (15). 
Tumor cells may also induce the endothelial expression of pro-inflammatory cytokines, such as MCP-1, IL-6, and IL-8 by endothelial cells. These cytokines may also be released by the neoplastic cells in the tumor microenvironment, contributing to the recruitment of lymphocytes and monocytes, to the induction of CAMs, to the promotion of angiogenesis (16) and, in bone metastases, to the recruitment and differentiation of osteoclast precursors.

The goal of this study was to analyze the effect of a panel of RCC lines on the expression of endothelial CAMs and proinflammatory cytokines, that may be important in the pathogenesis of osteolytic bone metastases from RCC.

\section{Materials and methods}

Four separate experiments were performed for adhesion molecule on HUVEC cultures, each isolated from a different donor. In each experiment, HUVEC from a single donor were used and each sample was tested in triplicate. The cell number, evaluated by crystal violet staining after CAM-EIA, was comparable under the different conditions (data not shown).

Cell cultures. HUVEC were harvested according to the method of Jaffe et al (17) and grown to confluence in medium M199 (Sigma, Steinbach, Germany) supplemented with $20 \%$ fetal calf serum (FCS) (Life Technologies, Karlsruhe, Germany), 2 mM L-glutamine (Glutamax I, Life Technologies, Karlsruhe, Germany), $100 \mathrm{UI} / \mathrm{ml}$ of penicillin (Invitrogen, Carlsbad, CA, USA), $100 \mu \mathrm{g} / \mathrm{ml}$ of streptomycin (Invitrogen), $25 \mu \mathrm{g} / \mathrm{ml}$ of sodium heparin (Sigma) and $25 \mu \mathrm{g} / \mathrm{ml}$ of endothelial growth factor supplement (ECGS) (Becton-Dickinson, Bedford, MA) (HUVEC medium) in tissue culture flasks precoated with $0.2 \%$ gelatine in water (Sigma). Renal carcinoma bone metastasis cells (CRBM 1990), previously isolated and characterized from a bone metastasis of RCC (18), were used after 10 to 25 passages. Caki-1 and ACHN were purchased from ATCC (Manassas, VA, USA). The three human RCC lines were maintained in Ham's F12 medium modified by Coon (Sigma, St. Louis, MO, USA), supplemented with $10 \%$ FCS, $2 \mathrm{mM} \mathrm{L-glutamine,} 100 \mathrm{UI} / \mathrm{ml}$ of penicillin, $100 \mu \mathrm{g} / \mathrm{ml}$ of streptomycin (Coon's medium).

Preparation of supernatants. CRBM 1990, ACHN and Caki-1 cells were cultured for $72 \mathrm{~h}$ until confluency, then the conditioned media were collected, centrifuged for $5 \mathrm{~min}$ at 1,500 rpm to remove cell debris, aliquoted and stored at $-20^{\circ} \mathrm{C}$.

Quantification of expression of cell adhesion molecules by enzyme immunoassay (CAM-EIA). HUVEC were seeded on fibronectin-coated (5 $\mu \mathrm{g} / \mathrm{ml})$ (Roche, Mannheim, Germany) 96-well microtiter plates $\left(1.6 \times 10^{4}\right.$ cells/well $)$ and after $24 \mathrm{~h}$ were stimulated with $50 \%$ HUVEC medium $+50 \%$ CRBM 1990, ACHN or Caki-1-conditioned media. The negative controls were both HUVEC incubated with 50\% HUVEC medium $+50 \%$ Ham's F12 medium and HUVEC incubated with $100 \%$ HUVEC medium. The positive control was lipopolysaccharide (endotoxin) LPS $(1 \mu \mathrm{g} / \mathrm{ml}$ in HUVEC medium) (lipopolysaccharide from E. coli 0111:B4, Sigma). The incubation time was $4 \mathrm{~h}$ for E-selectin, $24 \mathrm{~h}$ for ICAM-1, and $4 \mathrm{~h}$ and $24 \mathrm{~h}$ for VCAM-1. After incubation, HUVEC were washed twice with Dulbecco phosphate-buffered saline (DPBS) (BioWhittaker, Verviers, Belgium), fixed in methanol: ethanol (2:1) for $15 \mathrm{~min}$, washed three times with DPBS and incubated with Blocking Buffer (Roche) containing $1 \% \mathrm{H}_{2} \mathrm{O}_{2}$ at $37^{\circ} \mathrm{C}$ for $30 \mathrm{~min}$. Then the cells were incubated with the primary antibody for $45 \mathrm{~min}$ at $37^{\circ} \mathrm{C}$. Primary antibodies were monoclonal anti-E-selectin antibody $(0.5 \mu \mathrm{g} / \mathrm{ml}$, BMS 110 , Bender, Vienna, Austria), monoclonal anti-ICAM-1 antibody $(0.125 \mu \mathrm{g} / \mathrm{ml}$, BMS 108 , Bender $)$, monoclonal anti-VCAM antibody $(0.5 \mu \mathrm{g} / \mathrm{ml}, \mathrm{MON} 6017$, Monosan, Uden, The Netherlands). To check the specificity of the immunoreaction the isotype mouse IgG2a-ve was used as a control $(0.5 \mu \mathrm{g} / \mathrm{ml}$, CBL601, Cymbus Biotechnology, Hamburg, Germany) for E-selectin and mouse IgG1-ve $(1 \mu \mathrm{g} / \mathrm{ml}$, CBL600, Cymbus Biotechnology) was used as a control for VCAM-1 and ICAM-1. After three washes with DPBS the cells were exposed to the secondary antibody, antimouse IgG biotinylated 1:800 (RPN 1177, Amersham, Freiburg, Germany). Signals were enhanced by the biotin-streptavidin system (Amersham) and color reaction was performed using peroxidase-catalyzed o-phenylenediamine (Sigma). The reaction was stopped with $\mathrm{HCl} 3 \mathrm{M}$. The product of the reaction was transferred in a new clean plate and the adsorbance was determined at $492 \mathrm{~nm}$, while the cells were stained with crystal violet (5).

Crystal violet staining. After the CAM-EIA the cells were washed twice with DPBS and incubated with $0.1 \%$ crystal violet in water for $20 \mathrm{~min}$ at room temperature. Then the cells were washed with distilled water and treated with acetic acid $33 \%$ in water for $15 \mathrm{~min}$. The adsorbance was determined at $600 \mathrm{~nm}$.

RT-PCR analysis. HUVEC were seeded into a 6-well plate at a concentration of $4 \times 10^{5}$ cells/well and suspended in serumadded medium. After $24 \mathrm{~h}$ at $37^{\circ} \mathrm{C}$, the medium was replaced respectively with non-conditioned medium, LPS-added medium $(1 \mu \mathrm{g} / \mathrm{ml}), 50 \%$ CRBM 1990-conditioned medium, $50 \%$ ACHN-conditioned medium, 50\% Caki-conditioned medium. After $6 \mathrm{~h}$, total cellular RNA was isolated using Qia-shredders and RNeasy mini kit (Qiagen $\mathrm{GmbH}$, Hilden, Germany). Total cellular RNA was isolated also from ACHN, Caki-1 and CRBM 1990 at confluence using the same method. To avoid genomic DNA contamination, RNA samples were treated with Dnase I (RNase Free DNase, Qiagen GmbH, Hilden, Germany). Reverse transcription was performed using Omniscript RT kit (Qiagen $\mathrm{GmbH}$ ). On the cDNA, PCR reactions were performed using Taq PCR Core kit (Qiagen $\mathrm{GmbH})$. GenBank ${ }^{\mathrm{TM}}$ accession number of the cDNA sequences and the sizes of amplified fragments analized are: ß-actin (NM_001101; 574 bp), ICAM-1 (J03132; 395 bp), Eselectin (AF540378; 304 bp), VCAM (NM_001078; 282 bp), MCP-1 (S71513; 217 bp), granulocyte-macrophage colony stimulating factor (GM-CSF) (M13207; 196 bp), IL-8 (M28130;172 bp) and IL-6 (M14584; 173 bp). PCR primer sequences are: $ß$-actin (5'-AGCATTTGCGGTGGACG ATGGAG-3' and 5'-GACCTGACTGACTACCTCATGA3'), ICAM-1 (5'-TCATCACTGTGGTAGCAGCC-3' and 5'GTCTTGCTCCTTCCTCTTGG-3'), E-selectin (5'-TAC ACTTGCAAGTGTGACCC-3' and 5'-TGTCACAGCATCA 
Table I. Expression of adhesion molecules by HUVEC incubated with the conditioned media from renal carcinomas cell cultures (arithmetic mean, standard error and significance; ${ }^{\mathrm{p}} \mathrm{p}<0.05$ vs. negative control).

\begin{tabular}{lcccc}
\hline & & & VCAM (adsorbance) \\
\cline { 3 - 5 } & $\begin{array}{c}\text { ICAM-1 } \\
\text { (adsorbance) } 24 \mathrm{~h}\end{array}$ & $\begin{array}{c}\text { E-selectin } \\
\text { (adsorbance) } 4 \mathrm{~h}\end{array}$ & $4 \mathrm{~h}$ & $24 \mathrm{~h}$ \\
\hline Medium 199 (basal expression) & $0.097 \pm 0.021$ & $0.057 \pm 0.020$ & $0.028 \pm 0.016$ & $0.066 \pm 0.032$ \\
Coon's (negative control) & $0.079 \pm 0.011$ & $0.066 \pm 0.029$ & $0.024 \pm 0.012$ & $0.032 \pm 0.015$ \\
LPS (positive control) & $1.955 \pm 0.220^{\mathrm{a}}$ & $2.289 \pm 0.049^{\mathrm{a}}$ & $0.689 \pm 0.183^{\mathrm{a}}$ & $0.366 \pm 0.105$ \\
ACHN conditioned medium & $0.110 \pm 0.016$ & $0.211 \pm 0.059$ & $0.044 \pm 0.026$ & $0.027 \pm 0.007$ \\
Caki-1 conditioned medium & $0.485 \pm 0.110^{\mathrm{a}}$ & $0.400 \pm 0.136$ & $0.042 \pm 0.009$ & $0.036 \pm 0.017$ \\
CRBM 1990 conditioned medium & $0.113 \pm 0.011^{\mathrm{a}}$ & $0.259 \pm 0.097$ & $0.062 \pm 0.035$ & $0.034 \pm 0.005$ \\
\hline
\end{tabular}

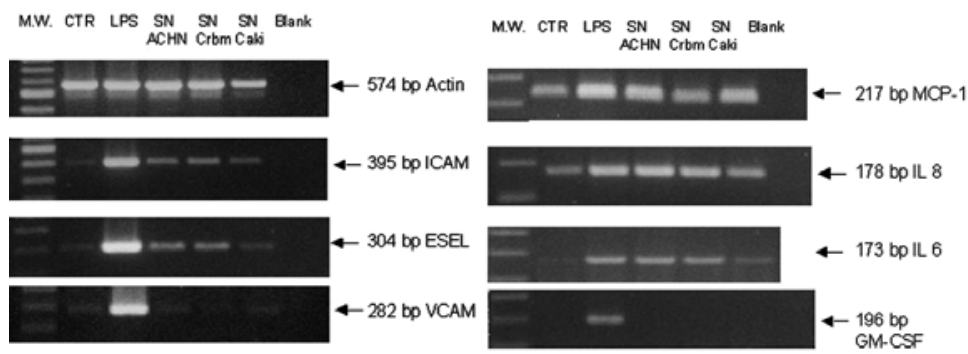

Figure 1. ICAM-1, E-selectin, VCAM-1, MCP-1, IL-8, IL-6 and GM-CSF mRNA expression by HUVEC stimulated with LPS or renal cancer cell conditioned media (representative pictures). The treatment with LPS or RCC conditioned media induced evident up-regulation of ICAM and E-selectin in HUVEC. A cytokine-specific mRNA (namely MCP-1, IL-6 and IL-8) increase was also evident in HUVEC treated with RCC conditioned media. VCAM and GM-CSF mRNA did not show any consistent variation in RCC conditioned media treated HUVEC.

CACTCAACC-3'), VCAM (5'-TCTCATTGACTTGCAGC ACC-3' and 5'-ACTTGACTGTGATCGGCTTCC-3'), MCP-1 (5'-CAGTCACCTGCTGTTATAACTTC-3' and 5'-GTGA GTGTTCAAGTCTTCGGAG-3'), granulocyte-macrophage colony stimulating factor (GM-CSF) (5'-CTGCTGCTGAGA TGAATGAAACAG-3' and 5'-GCACAGGAAGTTTCCG GGGT-3'), IL-8 (5'-CATGACTCCAAGCTGGC CGTG-3' and 5'-CCACTCTCAATCACTCTCAGTTC-3'), and IL-6 (5'-GATGCAATAACCACCCCTGACCC-3' and 5'-CAATC TGAGGTGCCCATGCTA-3'). The PCR consisted of one cycle at $94^{\circ} \mathrm{C}$ for 2 min and then 35 cycles (only for $\beta$-actin 30 cycles) at $94^{\circ} \mathrm{C}$ for $60 \mathrm{sec}$, annealing $\left(65^{\circ} \mathrm{C}\right.$ for $\mathrm{B}$-actin and IL- $8 ; 57^{\circ} \mathrm{C}$ for ICAM- $1 ; 52^{\circ} \mathrm{C}$ for IL- $6 ; 55^{\circ} \mathrm{C}$ for MCP-1 and GM-CSF; $62^{\circ} \mathrm{C}$ for E-selectin and VCAM) for $30 \mathrm{sec}$ and extension at $72^{\circ} \mathrm{C}$ for $30 \mathrm{sec}$, with a final extension at $72^{\circ} \mathrm{C}$ for $7 \mathrm{~min}$. Products were separated by electrophoresis using $1 \%$ agarose gel stained with ethidium bromide $(0.5 \mu \mathrm{g} / \mathrm{ml})$. DNA Ladder $100 \mathrm{bp}$ was run in parallel as a molecular weight marker (Bio-Rad). The cDNA signals were normalized to $\beta$-actin signals determined in parallel for each sample.

Immunostaining for E-selectin and ICAM-1. HUVEC were seeded on fibronectin-coated $(10 \mu \mathrm{g} / \mathrm{ml})$ (Roche) 8-well chamber slides $\left(4 \times 10^{4}\right.$ cells/well) and grown for $24 \mathrm{~h}$. Then the monolayers were stimulated with LPS $(1 \mu \mathrm{g} / \mathrm{ml})$ or $50 \%$ HUVEC medium $+50 \%$ CRBM 1990, ACHN or Caki-1conditioned media. The negative control were HUVEC treated with 50\% HUVEC medium $+50 \%$ Ham's F12 medium. The incubation times were $6 \mathrm{~h}$ for E-selectin or $24 \mathrm{~h}$ for ICAM-1.
The cells were fixed with p-formaldehyde $3.7 \%$ in PBS, then permeabilized with Hepes Triton-X $0.2 \%$ for $10 \mathrm{~min}$ (E-Sel) or $5 \mathrm{~min}$ (ICAM-1) and washed with PBS. Then the cells were incubated for $1 \mathrm{~h}$ with the primary monoclonal antibody anti-ELAM-1 (0.5 $\mu \mathrm{g} / \mathrm{ml}$, MON 6010, Monosan) 1:50 or anti-CD54 (anti-ICAM-1) 1:100 (MEM 112 Monosan). The primary antibodies were diluted in PBS $+3 \%$ bovine serum albumin (BSA) (Sigma). After three washes with PBS, the cells were exposed to the secondary antibody, goat fluorescent antimouse (A-11029, AlexaFluor, Molecular Probes, Leiden, The Netherlands) 1:1000 in PBS $+3 \%$ BSA (Sigma) for $1 \mathrm{~h}$. Actin cytoskeleton was stained using rhodamine-phalloidin fluorescent dye $0.06 \mathrm{mM}$ (Molecular Probes, Eugene, USA) in the dark for $30 \mathrm{~min}$. The nuclei were counterstained with propidium iodide $(0.5 \mu \mathrm{g} / \mathrm{ml})$ (Sigma) or Hoechst Dye 33342 (1 $\mu \mathrm{g} / \mathrm{ml})$ (Molecular Probes).

Statistical analysis. Statistical analysis was performed with the StatView ${ }^{\mathrm{TM}}$ 5.0.1 software for Windows (SAS Institute Inc., Cary, NC). The results were reported as the arithmetic mean and standard error (mean \pm SEM). The statistical analysis of the effects of conditioned media on HUVEC was made by the Student's t-test for paired samples. The level of statistical significance was set at $\mathrm{p}<0.05$.

\section{Results}

ICAM-1 expression induced by RCC supernatants. Since under basal conditions there were no significant differences in ICAM-1 expression in HUVEC depending on the culture 

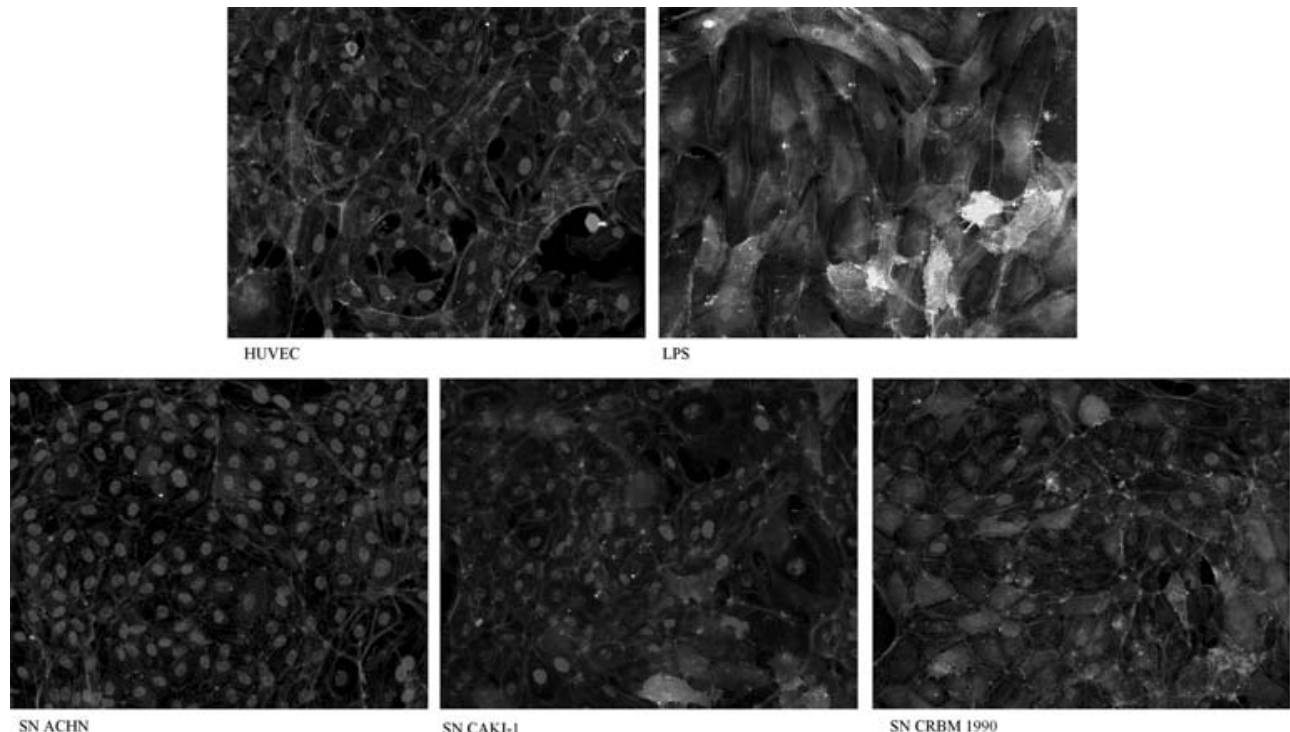

SNCAKI-I

SN CRBM 1990

Figure 2. Effect of conditioned media from CRBM 1990, ACHN and Caki-1 on ICAM-1 expression by HUVEC (representative pictures). HUVEC were stained with endothelial cell-specific anti-CD54 and nuclei were stained with Hoechst dye. Actin cytoskeleton was stained using rhodamine-phalloidin fluorescent dye. RCC conditioned media and LPS induced a higher expression of ICAM-1 on HUVEC.

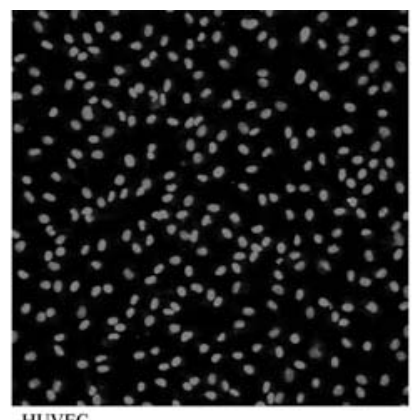
HUVEC

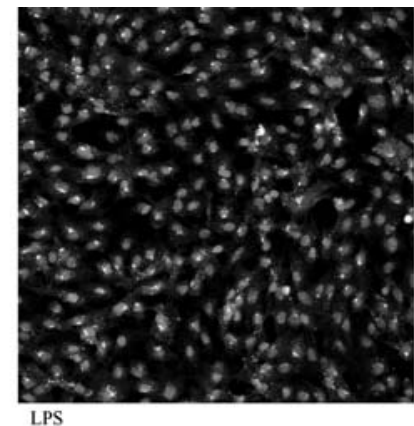

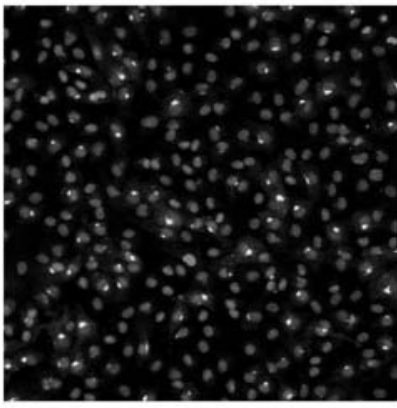

SN ACHN

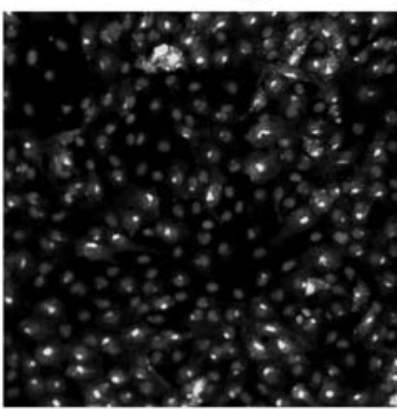

SN CAKI-1

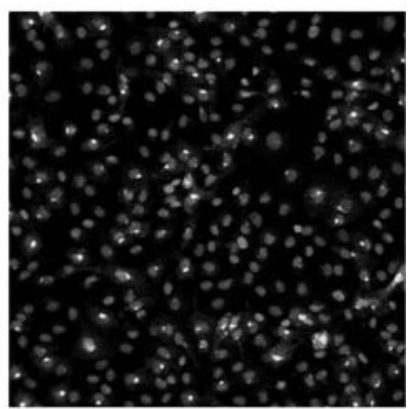

SN CRBM 1990

Figure 3. Effect of conditioned media from CRBM 1990, ACHN and Caki-1 on E-selectin expression by HUVEC (representative pictures). HUVEC were stained with endothelial cell-specific anti-ELAM-1 and nuclei were counterstained with propidium iodide. An evident expression of E-selectin was induced by LPS and RCC conditioned media on HUVEC.

medium (medium M199 or Coon's medium), subsequent experiments were done using Coon's medium. The stimulation with LPS induced a significantly higher ICAM-1 expression in HUVEC, in agreement to previous studies (5). After 24-h continuous exposure of HUVEC with RCC conditioned media, ICAM-1 expression was always increased compared to unstimulated culture conditions (Table I).

These findings were confirmed by RT-PCR. In fact, ICAM-1-specific mRNA was not expressed by HUVEC under basal conditions but was increased by LPS treatment. The conditioned media from ACHN, CRBM 1990 and Caki-1 induced an increase in ICAM-1 mRNA expression by HUVEC (Fig. 1). Similar results were obtained by immunostaining with ICAM-1 antibody (Fig. 2).

E-selectin expression induced by RCC supernatants. There were no significant differences in E-selectin expression in HUVEC cultured in medium 199 or Coon's medium. The stimulation with LPS induced a significantly higher E-selectin expression, in agreement to previous studies (5). Incubation 

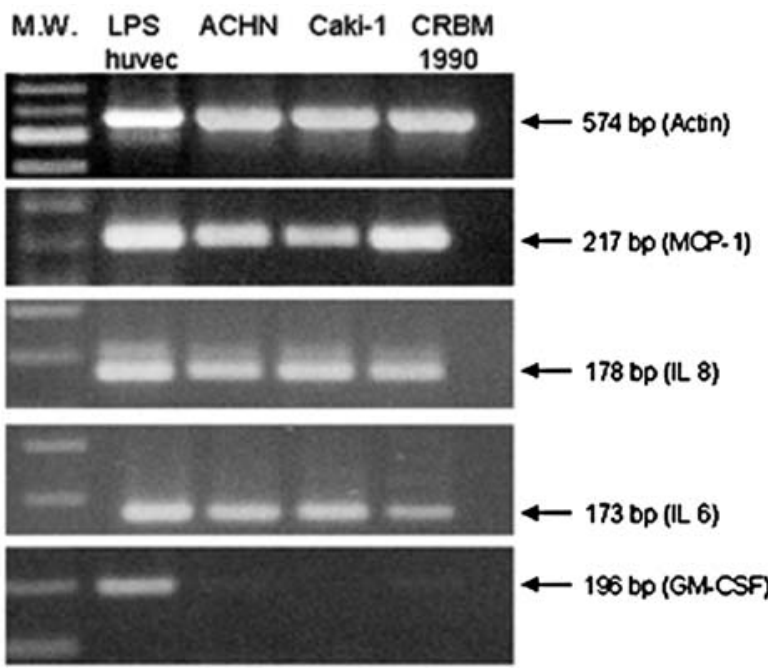

Figure 4. MCP-1, IL-8, IL-6 and GM-CSF mRNA expression by HUVEC stimulated with LPS, CRBM 1990, ACHN and Caki-1 (representative pictures). RCC cells and HUVEC stimulated by LPS showed an evident mRNA expression of MCP-1, IL-6 and IL-8, while only HUVEC stimulated by LPS produced GM-CSF.

of HUVEC with the conditioned medium from the three RCC lines always exhibited a higher level of E-selectin expression (Table I). E-selectin mRNA was not expressed by HUVEC under basal conditions but was increased after LPS stimulation. E-selectin mRNA expression was induced by the conditioned media from ACHN and CRBM 1990, but not by Caki-1 (Fig. 1). Immunostaining confirmed an increased expression of E-selectin in HUVEC treated with the supernatants of all of the three RCC cell lines (Fig. 3).

$V$-CAM-1 expression induced by RCC supernatants. There were no significant differences in VCAM-1 induction between medium M199 and Coon's medium. LPS induced a significant VCAM-1 expression after $4 \mathrm{~h}$, according to literature. The conditioned media from carcinomas did not induce significant variations in VCAM expression either after 4 or $24 \mathrm{~h}$ (Table I). As in the literature (5), VCAM-1-specific mRNA was not expressed by HUVEC under basal conditions, but was significantly induced by LPS. The conditioned media from carcinomas did not affect VCAM mRNA expression (Fig. 1).

Cytokine-specific mRNAs. By RT-PCR analysis, we observed that RCC cells produce MCP-1, IL-6, and IL-8, but not GM-CSF (Fig. 4).

As previously shown, HUVEC do not express GM-CSF or IL-6 mRNAs under basal conditions, but their expression is induced by LPS stimulation (5). The conditioned media from carcinomas did not affect GM-CSF expression. On the contrary, RCC conditioned media induced IL- 6 expression in HUVEC and increased the expression of both IL-8 and MCP-1 (Fig. 1).

\section{Discussion}

The cellular mechanisms responsible for local destruction of bone by tumor cells are largely dependent on an increase in osteoclast activity, although tumor cells may directly destroy bone by proteolytic activity (19). In particular, a characteristic of bone metastases from RCC is the presence of a purely lytic process that is mediated by osteoclast recruitment and activation and accompanied by a striking neo-vascularization. These phenomena may be so evident that entire bone segments are substituted by the tumor tissue and the hypervascularity at the site of metastasis is so evident that a pulsatile mass may be seen on inspection. Little is known on the mechanisms underlying these phenomena, moreover, the exact nature of the mediators of bone destruction and increased vascularity at the metastatic site are not fully elucidated.

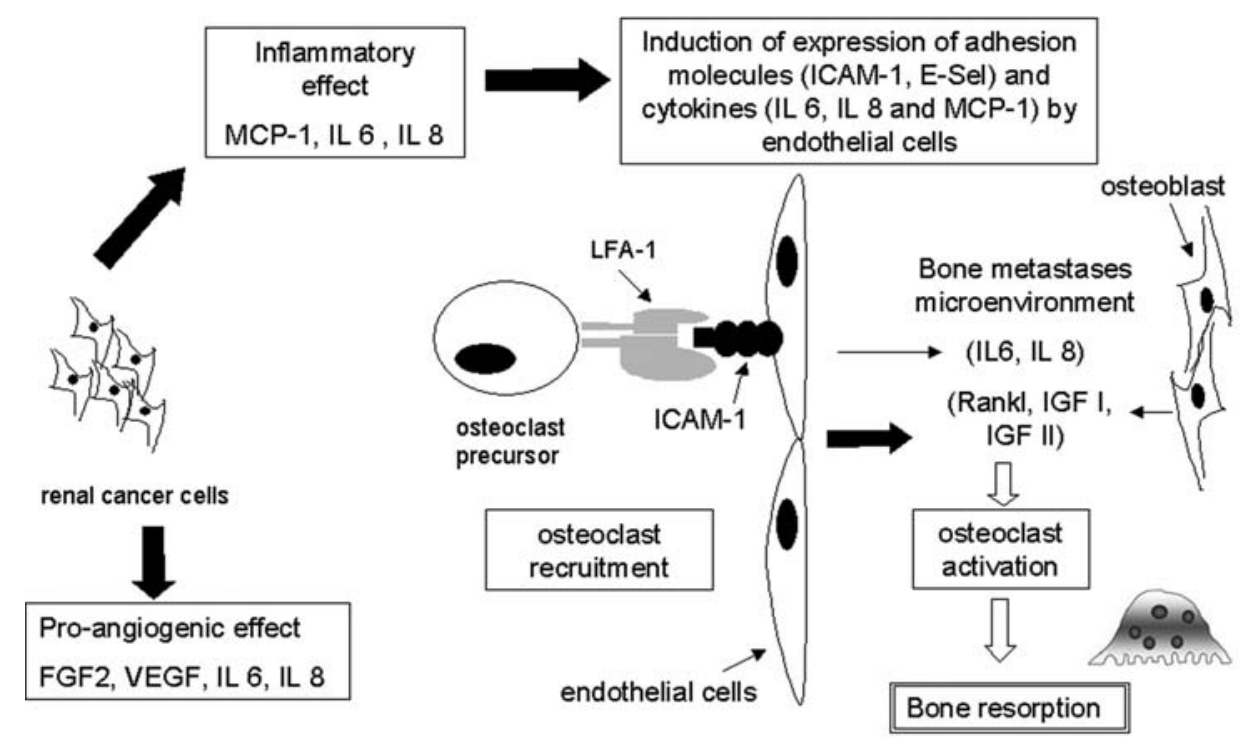

Figure 5. Schematic model of the hyphothesis of pro-inflammatory and osteolytic events in bone metastases from RCC. RCC secrete pro-inflammatory cytokines and induce the expression of CAMs, particularly ICAM-1 and E-Sel, by endothelial cells. The binding of LFA-1, expressed by osteoclast precursors, with ICAM-1, expressed by inflammed endothelium, might favour osteoclast recruitment. In bone metastases microenvironment, osteoclast activation is induced by local factors, such as IGF I, IGF II and Rankl and by IL-6 and IL-8, which are secreted by inflammed endothelium. These phenomena are potentiated by the pro-angiogenic activity of RCC. 
We investigated whether RCC cells secrete soluble factors that may enhance osteoclast recruitment and neo-angiogenesis. We also studied this tumor's ability to indirectly influence osteoclasts by acting on endothelial cells. By using a panel of RCC cell lines and HUVEC as a model, we were able to demonstrate that RCC not only produce a number of proinflammatory mediators, but also induce the expression of adhesion molecules, namely ICAM-1 and E-selectin, in HUVEC, suggesting the existence of a multiplex paracrine influence that may be relevant for the pathogenesis of bone metastasis of this type of tumor.

Frequent infiltration of RCC tissue with cells of the immune system, as well as rare spontaneous regressions and clinical responses to cytokine therapy, suggest that since RCC is immunogenic, it may benefit from the establishment of immunotherapy (20). The expression of IL-8, a cytokine that is implicated in angiogenesis and osteoclast recruitment, is significantly higher in lymph node metastases of RCC compared to primary tumors (3). Elevated levels of IL-6, an autocrine tumor growth factor produced by RCC cells, correlated with a poor outcome in patients with metastatic RCC (21). Serum levels of IL-6 were detectable in the majority of patients with metastatic renal cell carcinoma and showed a significant correlation to progression-free survival and overall survival (22). By RT-PCR we confirmed that RCC cells produce MCP-1, IL-6, and IL-8, three cytokines that may act as mediators of the inflammatory reaction elicited by RCC in a clinical setting. The recruitment of immune cells by cytokines produced by RCC cells is mediated by the induction of adhesion molecule expression by endothelial cells $(23,24)$. ICAM-1 mediates two important functional aspects of tumor biology, namely enhancement of tumor metastasis and mediation of host defense mechanisms such as lymphocytemediated tumor cytotoxicity (25). E-selectin is expressed by endothelial cells during inflammation and interact with leukocytes through sialyl-Lewis(x) and sialyl-Lewis(a) antigens. E-selectin may also be involved in tumor metastasis process, through the binding of tumor-associated glycoproteins and glycolipids, that have been reported as potential ligands for E-sel (26). High level of sialyl-Lewis(x) expression in renal cell carcinoma are crucial for tumor cell adhesion to the endothelium and metastasis (27). VCAM-1 favours monocyte and lymphocyte adhesion to endothelial cells and appears to be involved in the interaction between stromal cells and osteoclastic precursors, through the binding of $\alpha 4 \beta 1$ integrin (15).

In our study, RCC cells induced the expression of two adhesion molecules, namely ICAM-1 and E-selectin, by HUVEC endothelial cells both at the molecular and protein level. The increase of ICAM-1 and E-selectin expression, induced by RCC cells, is further potentiated by its ability to induce a pro-angiogenic effect through FGF-2 and VEGF (18).

The expansion of blood vessels through angiogenesis physically enables greater delivery of circulating preosteoclasts into the metastases site. CAMs expressed by endothelium stimulated by tumor cells can bind osteoclast precursors and favour transendothelial migration (11). ICAM-1, expressed by the endothelium, binds lymphocyte function-associated antigen-1 (LFA-1), which is expressed by the pre-osteoclast cell membrane. ICAM-1 was shown to be an important component of the mechanism by which cytokinepretreated HMVEC stimulated pre-osteoclasts transendothelial migration (11).

Osteoclasts activation and differentiation may be favoured by insulin growth factors I and II (IGF-I and IGF-II), two growth factors produced and stored in bone matrix (28) and receptor activator of NF- $\mathrm{KB}$ ligand (RANKL), secreted by osteoblasts $(29,30)$ in bone microenvironment.

Moreover, in our study, the expression of IL-6 and IL-8, inducing osteoclast activation (31), is increased in HUVEC stimulated with conditioned media from the carcinoma lines. The induction of the expression of ICAM-1, IL-6 and IL-8 in endothelial cells may favour pre-osteoclasts recruitment then osteoclast activation, contributing to osteolysis in bone metastases from renal carcinoma (Fig. 5).

These findings support the hypothesis that the peculiar immunogenic properties of RCC activate a cascade of proinflammatory and osteolytic events that, in addition to proangiogenic effects of this tumor, may adversely affect the tumor-host interactions and lead to a clinically aggressive phenotype. Therapies aimed at the blockage of this complex network of events my be beneficial for the treatment of this tumor.

\section{Acknowledgements}

Supported by A.I.R.C. (Italian Association of Cancer Research) grant and the Ministry of Health in Italy.

\section{References}

1. Thurnher M, Radmayr C, Hobisch A, Bock G, Romani N, Bartsch $\mathrm{G}$ and Klocher H: Tumor-infiltrating $\mathrm{T}$ lymphocytes from renal-cell carcinoma express B7-1 (CD80): T-cell expansion by T-T cell co-stimulation. Int J Cancer 62: 559-564, 1995.

2. Holtl L, Zelle-Rieser C, Gander, Papesh C, Ramoner R, Bartsch G, Rogatsch H, Barsoum AL, Coggin JH Jr and Thurnher M: Immunotherapy of metastatic renal cell carcinoma with tumor lysate-pulsed autologous dendritic cells. Clin Cancer Res 8: 3369-3376, 2002.

3. Fukata S, Inoue K, Kamada M, Kawada C, Furihata M, Ohtsuki Y and Shuin T: Levels of angiogenesis and expression of angiogenesis-related genes are prognostic for organ-specific metastasis of renal cell carcinoma. Cancer 103: 931-942, 2005.

4. Aoki J, Yamamoto I, Hino M, Shigeno C, Kitamura N, Sone T, Shiomi K and Konishi J: Osteoclast-mediated osteolysis in bone metastasis from renal cell carcinoma. Cancer 62: 98-104, 1988.

5. Unger RE, Krump-Konvalinkova V, Peters K and Kirkpatrick CJ: In vitro expression of the endothelial phenotype: comparative study of primary isolated cells and cell lines, including the novel cell line HPMEC-ST1.6R. Microvasc Res 64: 384-397, 2002.

6. Steinbach F, Tanabe K, Alexander J, Edinger M, Tubbs R, Brenner W, Stockle M, Novick AC and Klein EA: The influence of cytokines on the adhesion of renal cancer cells to endothelium. J Urol 155: 743-748, 1966.

7. Dimitroff CJ, Lechpammer M, Long-Woodward D and Kutok JL: Rolling of human bone-metastatic prostate tumor cells on human bone marrow endothelium under shear flow is mediated by E-selectin. Cancer Res 64: 5261-5269, 2004.

8. Tei K, Kawakami-Kimura N, Taguchi O, Kumamoto K, Higashiyama S, Taniguchi N, Toda K, Kawata R, Hisa Y and Kannagi R: Roles of cell adhesion molecules in tumor angiogenesis induced by cotransplantation of cancer and endothelial cells to nude rats. Cancer Res 62: 6289-6296, 2002.

9. Yasuda M, Shimizu S, Ohhinata K, Naito S, Tokuyama S, Mori Y, Kiuchi Y and Yamamoto T: Differential roles of ICAM-1 and E-selectin in polymorphonuclear leukocyte-induced angiogenesis. Am J Physiol Cell Physiol 282: C917-C925, 2002 . 
10. McGowan NW, Walker EJ, Macpherson H, Ralston SH and Helfrich MH: Cytokine-activated endothelium recruits osteoclast precursors. Endocrinology 142: 1678-1681, 2001.

11. Kindle L, Rothe L, Kriss M, Osdoby P and Collin-Osdoby P: Human microvascular endothelial cell activation by IL- 1 and TNF- $\alpha$ stimulates the adhesion and transendothelial migration of circulating human $\mathrm{CD} 14^{+}$monocytes that develop with RANKL into functional osteoclasts. J Bone Miner Res 21: 193-206, 2006.

12. Lavigne P, Benderdour M, Shi Q, LajeunesseD and Fernandes JC: Involvement of ICAM-1 in bone metabolism: a potential target in the treatment of bone diseases? Expert Opin Biol Ther 5: 313-320, 2005

13. Roodman GD: Cell biology of the osteoclast. Exp Hematol 27: 1229-1241, 1999.

14. Harada H, Kukita T, Kukita A, Iwamoto $\mathrm{Y}$ and Iijima $\mathrm{T}$ : Involvement of lymphocyte function-associated antigen-1 and intercellular adhesion molecule-1 in osteoclastogenesis: a possible role in direct interaction between osteoclast precursors. Endocrinology 139: 3967-3975, 1988.

15. Akatsu T, Ono K, Murakami T, Katayama Y, Nishikawa M, Wada S, Yamamoto M, Kugai N, Matsuura N, Takada Y and Nagata N: Chinese hamster ovary cells expressing alpha4beta1 integrin stimulate osteoclast formation in vitro. J Bone Miner Res 13: 1251-1259, 1988.

16. Coussens LM and Werb Z: Inflammation and cancer. Nature 420: 860-867, 2002

17. Jaffe EA, Nachman RL, Becker CG and Minick CR: Culture of human endothelial cells derived from umbilical veins. Identification by morphologic and immunologic criteria. J Clin Invest 52: 2745-2756, 1973 .

18. Avnet S, Cenni E, Granchi D, Perut F, Amato I, Battistelli L, Brandi ML, Giunti A and Baldini N: Isolation and characterization of a new cell line from a renal carcinoma bone metastasis. Anticancer Res 24: 1705-1711, 2004.

19. Bjornland K, Flatmark K, Pettersen S, Aaasen AO, Fodstad O and Maelandsmo GM: Matrix metalloproteinases participate in osteosarcoma invasion. J Surg Res 127: 151-156, 2005

20. Mulders P, Figlin R, deKernion JB, Wiltrout R, Linehan M, Parkinson D, deWolf W and Belldegrun A: Renal cell carcinoma: recent progress and future directions. Cancer Res 57: 5189-5195, 1997.

21. Blay JY, Negrier S, Combaret V, Attali S, Goillot E, Merrouche Y, Mercatello A, Ravault A, Tourani JM and Moskovtchenko JF: Serum level of interleukin 6 as a prognosis factor in metastatic renal cell carcinoma. Cancer Res 52: 3317-3322, 1992.
22. Negrier S, Perol D, Menetrier-Caux C, Escudier B, Pallardy M, Ravaud A, Douillard JY, Chevreau C, Lasset C and Blay JY: Interleukin-6, interleukin-10, and vascular endothelial growth factor in metastatic renal cell carcinoma: prognostic value of interleukin-6 - from the Groupe Francais d'Immunotherapie. J Clin Oncol 22: 2371-2378, 2004.

23. Muller WA: Leukocyte-endothelial-cell interactions in leukocyte transmigration and the inflammatory response. Trends Immunol 24: 327-334, 2003

24. Watson C, Whittaker S, Smith N, Vora AJ, Dumonde DC and Brown KA: IL-6 acts on endothelial cells to preferentially increase their adherence for lymphocytes. Clin Exp Immunol 105: 112-119, 1996.

25. Tanabe K, Campbell SC, Alexander J, Steinbach F, Edinger MG, Tubbs RR, Novick AC and Klein EA: Molecular regulation of intercellular adhesion molecule 1 (ICAM-1) expression in renal cell carcinoma. Urol Res 25: 231-238, 1997.

26. Mathieu S, Prorok M, Benoliel AM, Uch R, Langlet C, Bongrand P, Gerolami R and El-Battari A: Transgene expression of alpha(1,2)-fucosyltransferase-I (FUT1) in tumor cells selectively inhibits sialyl-Lewis $\mathrm{x}$ expression and binding to E-selectin without affecting synthesis of sialyl-Lewis a or binding to P-selectin. Am J Pathol 164: 371-383, 2004.

27. Tozawa K, Okamoto T, Kawai N, Hashimoto Y, Hayashi Y and Kohri K: Positive correlation between sialyl Lewis X expression and pathologic findings in renal cell carcinoma. Kidney Int 67: 1391-1396, 2005

28. Colucci S, Mori G, Vaira S, Brunetti G, Greco G, Mancini L, Simone GM, Sardelli F, Koverech A, Zallone A and Grano M: L-carnitine and isovaleryl L-carnitine fumarate positively affect human osteoblast proliferation and differentiation in vitro. Calcif Tissue Int 76: 458-465, 2005.

29. Humphrey EL, Williams JH, Davie MW and Marshall MJ: Effects of dissociated glucocorticoids on OPG and RANKL in osteoblastic cells. Bone 38: 652-661, 2005.

30. Matsuo K and Irie N: Osteoclast-osteoblast communication. Arch Biochem Biophys 473: 201-209, 2008.

31. Konig B, Steinbach F, Janocha B, Drynda A, Stumm M, Philipp C, Allhoff EP and Konig W: The differential expression of proinflammatory cytokines IL-6, IL-8 and TNF-alpha in renal cell carcinoma. Anticancer Res 19: 1519-1524, 1999. 